\title{
Task 21 - Evaluation of Artificial Freeze Crystallization and Natural Freeze-Thaw Processes for the Treatment of Contaminated Groundwater at the Strachan Gas Plant in Alberta, Canada-Sour Gas Remediation Technology R\&D
}

\section{RECEIVED}

JUL 301997

\section{Topical Report March 1997}

Work Performed Under Contract No.: DE-FC21-93MC30098

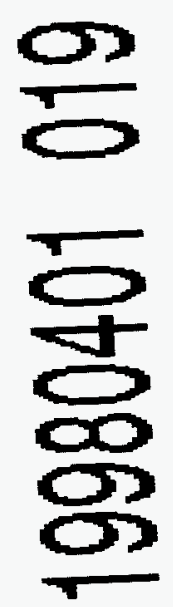

For

U.S. Department of Energy

Office of Fossil Energy

Federal Energy Technology Center

Morgantown Site

P.O. Box 880

Morgantown, West Virginia 26507-0880

By

Energy \& Environmental Research Center

University of North Dakota

P. O. Box 9018

Grand Forks, North Dakota 58202-9018

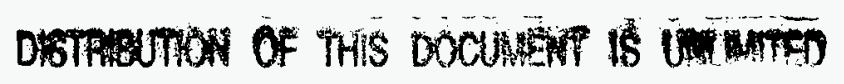
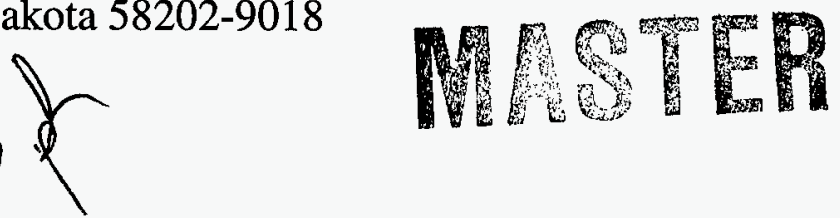

IDTC QUALTY TNESEUTED \& 


\section{Disclaimer}

This report was prepared as an account of work sponsored by an agency of the United States Government. Neither the United States Government nor any agency thereof, nor any of their employees, makes any warranty, express or implied, or assumes any legal liability or responsibility for the accuracy, completeness, or usefulness of any information, apparatus, product, or process disclosed, or represents that its use would not infringe privately owned rights. Reference herein to any specific commercial product, process, or service by trade name, trademark, manufacturer, or otherwise does not necessarily constitute or imply its endorsement, recommendation, or favoring by the United States Government or any agency thereof. The views and opinions of authors expressed herein do not necessarily state or reflect those of the United States Government or any agency thereof. 


\section{EERC DISCLAIMER}

LEGAL NOTICE This research report was reviewed and submitted by the Energy \& Environmental Research Center (EERC), an agency of the University of North Dakota, as an account of work sponsored by Department of Energy (DOE) and Canadian Association of Petroleum Producers (CAPP). Because of the research nature of the work performed, neither the EERC nor any of its employees makes any warranty, express or implied, or assumes any legal liability or responsibility for the accuracy, completeness, or usefulness of any information, apparatus, product, or process disclosed, or represents that its use would not infringe privately owned rights. Reference herein to any specific commercial product, process, or service by trade name, trademark, manufacturer, or otherwise does not necessarily constitute or imply its endorsement or recommendation by the EERC.

\section{ACKNOWLEDGMENT}

This report was prepared with the support of the U.S. Department of Energy (DOE) Federal Energy Technology Center Cooperative Agreement No. DE-FC21-93MC30098. However, any opinions, findings, conclusions, or recommendations expressed herein are those of the authors(s) and do not necessarily reflect the views of DOE.

\section{DISCLAIMER}

This report was prepared as an account of work sponsored by an agency of the United States Government. Neither the United States Government, nor any agency thereof, nor any of their employees makes any warranty, express or implied, or assumes any legal liability or responsibility for the accuracy, completeness, or usefulness of any information, apparatus, product, or process disclosed or represents that its use would not infringe privately owned rights. Reference herein to any specific commercial product, process, or service by trade name, trademark, manufacturer, or otherwise does not necessarily constitute or imply its endorsement, recommendation, or favoring by the United States Government or any agency thereof. The views and opinions of authors expressed herein do not necessarily state or reflect those of the United States Government or any agency thereof. 


\section{TABLE OF CONTENTS}

LIST OF FIGURES $\ldots \ldots \ldots \ldots \ldots \ldots \ldots \ldots \ldots \ldots \ldots \ldots \ldots$ ii

LIST OF TABLES $\ldots \ldots \ldots \ldots \ldots \ldots \ldots \ldots \ldots \ldots \ldots \ldots \ldots \ldots \ldots$

EXECUTIVE SUMMARY $\ldots \ldots \ldots \ldots \ldots \ldots \ldots \ldots \ldots \ldots$ iii

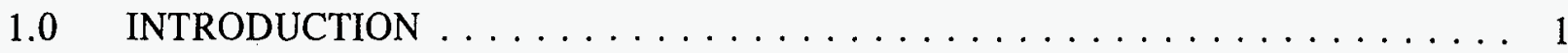

2.0 RTC-EERC FREEZE CRYSTALLIZATION WATER PURIFICATION PROCESS

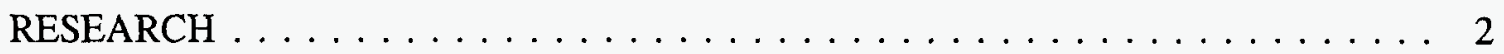

2.1 RTC-EERC Freeze Crystallization Water Purification Process Work Plan . . . 2

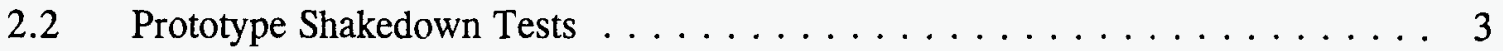

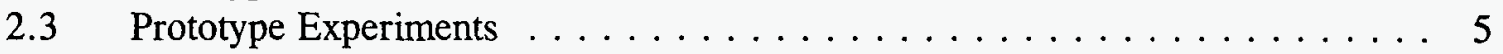

3.0 NATURAL FREEZE-THAW PROCESS RESEARCH $\ldots \ldots \ldots \ldots \ldots \ldots \ldots$

3.1 Natural Freeze-Thaw Process Research Work Plan . . . . . . . . . . . . . . 6

3.2 Review of Strachan Plant Contaminated Groundwater Characterization Data . . 6

3.3 Evaluation of Process and Environmental Constraints . . . . . . . . . 6

3.4 Laboratory-Scale Natural Freeze Crystallization Simulation . . . . . . . . . . . . 6

$4.0 \quad$ SUMMARY AND CONCLUSIONS $\ldots \ldots \ldots \ldots \ldots \ldots \ldots \ldots \ldots$

4.1 Artificial Freeze Crystallization Water Purification Process . . . . . . . . . . . . 9

4.2 Natural Freeze Crystallization Water Purification Process . . . . . . . . . . . . 10

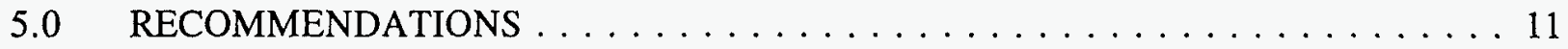

5.1 Artificial Freeze Crystallization Water Purification Process . . . . . . . . . . 11

5.2 Natural Freeze Crystallization Water Purification Process . . . . . . . . . . . 11 


\section{LIST OF FIGURES}

1 RTC-UNDEERC freeze crystallization water purification process flowchart $\ldots \ldots \ldots \ldots$

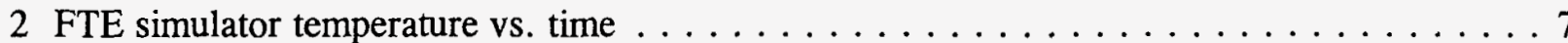

3 Electrical conductivity of melt fractions freeze-thaw simulation of Strachan Plant P\&T water . 8

4 FTE simulation product yield freeze-thaw simulation of Strachan Plant P\&T water $\ldots \ldots$

\section{LIST OF TABLES}

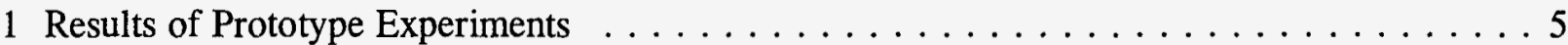

2 Results of Chemical Analyses of Strachan Plant P\&T Water Freeze-Thaw Simulation Process

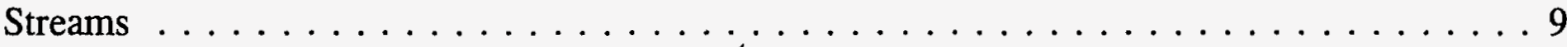




\section{EVALUATION OF ARTIFICIAL FREEZE CRYSTALLIZATION AND NATURAL FREEZE-THAW PROCESSES FOR THE TREATMENT OF CONTAMINATED GROUNDWATER AT THE STRACHAN GAS PLANT IN ALBERTA, CANADA-SOUR GAS REMEDIATION TECHNOLOGY R\&D}

\section{EXECUTIVE SUMMARY}

During the period from 1993 to 1996, a long-term program was initiated to conduct remediation research at the Strachan Gas Plant in Alberta, Canada. As part of this research program, optimization of the existing pump-and-treat (P\&T) facility was of interest. The costeffective treatment of contaminated groundwater produced from the P\&T system was complicated by several factors, including 1) increased cost and reduced effectiveness of most water treatment processes because of the cold temperatures and severe winter conditions prevalent in Alberta, 2) interference caused by the mixture of inorganic and organic contaminants found in the groundwater that can reduce the effectiveness of many water treatment processes, and 3) pretreatment to prevent scaling in existing treatment process unit operations caused by the iron, manganese, and hardness of the contaminated groundwater.

The development and evaluation of two groundwater treatment processes were initiated during the project period, both of which use freeze crystallization for remediation of contamination. This research, sponsored by the Canadian Association of Petroleum Producers (CAPP) and the U.S. Department of Energy (DOE), was conducted by the Resource Technology Corporation (RTC) of Laramie, WY, under a subcontract from the University of North Dakota Energy \& Environmental Research Center (EERC). One of the processes developed and evaluated for remediation of contaminated water associated with sour gas production and processing uses artificial refrigeration to freeze and, subsequently, purify the water. This process is similar to commercially available freeze crystallization water purification processes successfully in use in both the United States and Canada. The design of this unit has the potential to reduce both unit size and capital equipment requirements relative to those of existing commercial units. The second process under development during the project was a natural freeze-thaw process. This process utilizes naturally occurring atmospheric conditions to generate usable water from contaminated groundwater during the winter months.

A prototype of the RTC-EERC artificial freeze crystallization process was constructed, extensively shaken down, and modified. A series of ten experiments were conducted to begin the optimization of the artificial freeze crystallization process prototype. The study of the natural freeze-thaw process consisted of several steps, including review of chemical analyses from the Strachan plant contaminated groundwater; evaluation of the regulatory climate in Alberta, Canada; obtaining and compiling meteorological data for Rocky Mountain House, Alberta, Canada, to produce monthly estimates of daily average temperature cycles for use in the laboratory-scale natural freeze crystallization simulator; and performance of a 21-day simulation of the natural freeze crystallization process using samples of contaminated groundwater from the Strachan Plant.

Although the operation of the artificial freeze crystallization process prototype was not optimized for the treatment of contaminated groundwater, the process was shown to be capable of removing significant quantities of contaminants from the groundwater. The prototype successfully 
reduced the electrical conductivity (EC) of groundwater by $62 \%$ and increased the EC of the brine generated by $52 \%$ when compared to the contaminated feed. Modifications that should be made to improve the operability and efficiency of the prototype include increasing the operating pressure of the feed in the refrigerant evaporator heat exchanger, increasing the maximum centrifuge speed, improving the performance of the ice scraper and ice removal system for the prototype's centrifuge, and adding another air-liquid refrigerant evaporator to the centrifuge housing. If we assume that the prototype modifications result in the expected improvements in efficiency, the potential for commercial use of the process is promising. It appears that it would be prudent to continue to invest in the development of the artificial freeze crystallization process.

Since the start of this project, the natural freeze-thaw process has been demonstrated on a commercial scale in New Mexico. The natural freeze crystallization process appears to be suitable for use in treating contaminated groundwater from the Strachan Plant. Both the size of the Alberta, Canada, gas industry and the favorable climate for freezing imply that it would be beneficial to test the natural freeze-thaw process and apply the technology to the treatment of the natural gas industry's groundwater.

Additional laboratory-scale simulations should be conducted to provide supplementary information regarding the behavior of organic compounds. The use of the natural freeze crystallization process should be demonstrated at the Strachan Plant during a field test. 


\section{EVALUATION OF ARTIFICIAL FREEZE CRYSTALLIZATION AND NATURAL FREEZE-THAW PROCESSES FOR THE TREATMENT OF CONTAMINATED GROUNDWATER AT THE STRACHAN GAS PLANT IN ALBERTA, CANADA-SOUR GAS REMEDIATION TECHNOLOGY R\&D}

\subsection{INTRODUCTION}

The cost of remediating contaminated water generated in association with natural gas production and treatment is becoming an important economic and environmental concern. Economical methods for treatment, disposal, and/or reuse of these waters on a commercial scale would assist the natural gas industries in continuing to provide reasonably priced fuels to the consumer.

Freeze-thaw cycles have been investigated for many years as a means of purifying water or concentrating contaminants in water. The purification of water using freeze-thaw cycles is compatible with climates typical of Alberta during the winter months. Furthermore, both natural and artificial freezing technologies applied to water purification have been shown to be effective in removing both organics and inorganics from contaminated waters. The application of these technologies to the treatment of contaminated groundwater produced during pump-and-treat (P\&T) activities at the Strachan Plant is potentially cost-effective.

During the project period, a long-term program was initiated to conduct remediation research at the Strachan Gas Plant in Alberta, Canada. The cost-effective treatment of contaminated groundwater produced from the P\&T system there was complicated by several factors, including 1) increased cost and reduced effectiveness of most water treatment processes because of the cold temperatures and severe winter conditions prevalent in Alberta, 2) interference caused by the mixture of inorganic and organic contaminants found in the groundwater that can reduce the effectiveness of many water treatment processes, and 3) pretreatment to prevent scaling in existing treatment process unit operations caused by the iron, manganese, and hardness of the contaminated groundwater.

The development and evaluation of two groundwater treatment processes were initiated during the project period, both of which use freeze crystallization for remediation of contamination. This research, sponsored by the Canadian Association of Petroleum Producers (CAPP) and the U.S. Department of Energy (DOE), was conducted by the Resource Technology Corporation (RTC) of Laramie, Wyoming, under a subcontract from the University of North Dakota Energy \& Environmental Research Center (EERC).

One of the processes under development during this project uses artificial refrigeration to freeze and, subsequently, purify the contaminated groundwater. This process is similar to commercially available freeze crystallization water purification processes successfully in use in both the United States and Canada, although the design of this unit reduces size and capital equipment requirements relative to existing commercial units. A research plan to develop this treatment process was developed and included 1) construction of a prototype unit and experimental process evaluation, 2) on-site demonstration of the prototype unit at the Strachan Plant, and 3) process scaleup and economic evaluation. 
The other process developed and evaluated for remediation of contaminated water associated with sour gas production and processing was the natural freeze-thaw process. This process utilizes naturally occurring atmospheric conditions to generate usable water from contaminated groundwater during the winter months. A research program was devised to develop this treatment process for use at the Strachan Plant. The planned program consisted of 1) laboratory-scale process simulation, 2) on-site bench-scale demonstration at the Strachan Plant, and 3) process scaleup and preliminary economic analysis of the process for comparison to conventional treatment alternatives.

This research program was designed to permit commercial development of these two processes in a compressed time frame estimated at 3 to 5 years after the initial discussions with CAPP in 1992. Although significant progress was made regarding the development of the artificial freeze crystallization process, it is not yet ready for field demonstration. This report summarizes the research effort and its results.

\subsection{RTC-EERC FREEZE CRYSTALLIZATION WATER PURIFICATION PROCESS RESEARCH}

Research was performed to develop and demonstrate a cost-effective and viable freeze-thaw process using artificial refrigeration to freeze and, subsequently, purify the contaminated groundwater from the Strachan Gas Plant in Alberta, Canada. The specific objectives of the research included the following:

- Construct and operate a 6-gal/hr (1200-lb/day) prototype to purify contaminated groundwater from the Strachan Plant using artificial freezing technology.

- Demonstrate the effectiveness of the prototype for treating contaminated groundwater at the Strachan Plant.

- Acquire sufficient design data to optimize the operation of the unit when treating this particular groundwater.

- Test the prototype at the Strachan Plant.

- Design and determine the cost for a unit large enough to treat all of the contaminated groundwater produced at the Strachan Plant.

\subsection{RTC-EERC Freeze Crystallization Water Purification Process Work Plan}

The work plan consisted of the activities associated with constructing and shaking down the prototype unit, including acquiring materials and equipment, constructing the prototype unit, and initial testing of the unit. The prototype unit was to be tested for operability during shakedown. Each process unit was to be tested individually, and process controls and monitors were to be calibrated and alarms tested. After all units were operational, the integrated prototype was to be tested using groundwater having an elevated total dissolved solids (TDS) content. Any design modifications were to be completed, operational procedures evaluated, and the prototype modified as necessary. 
In addition to basic operability tests, shakedown also was to consist of preliminary testing of process behavior under a variety of conditions using product TDS levels as the measure of process performance. Parameters to be studied included centrifuge speed, groundwater feed rate, concentrate purge rate, wash water rate, and heat-exchanger outlet temperature. To reduce costs, chemical analyses of feed and product samples were not performed during the shakedown; rather, conductivity was monitored to provide an indication of relative TDS levels.

Following shakedown, experiments were planned that would provide preliminary data indicating the extent to which the process can remove contaminants from groundwater. Analytical data were to be used to evaluate the ability of the process to meet the required discharge water quality and to estimate the toxicity of the treated water. Evaluation of process operation during the experiments would estimate the stability of the process and controls with the goal of minimizing the labor required to operate the unit. Any equipment problems or downtime were to be recorded to estimate the maintenance requirements and downtime for large-scale process operation. The technical feasibility of the process and its suitability for use at the Strachan Plant were to be determined from the results of these evaluations.

The prototype demonstration was to take place at the Strachan Plant. The unit was to be transported to the plant, connected to the existing treatment system and services, and operated 8 hours per day for approximately three 5-day periods, followed by continuous operation for approximately 1 week. Sampling and analysis of products were to be conducted to confirm the demonstration unit's capability to perform at design rates and generate nontoxic treated water of a quality acceptable for discharge or reinjection. At least 12 chemical analyses of composite samples from the tests would be required to confirm the prototype remediation capabilities.

\subsection{Prototype Shakedown Tests}

A block flow diagram of the prototype unit is provided in Figure 1. Five tests were performed to shake down the prototype and prove basic operability. In addition, ten parametric tests were performed. Collectively, all 15 of the shakedown tests represented $85 \mathrm{hr}$ of operation. Basic shakedown testing of the prototype was conducted as follows. Individual process units were tested separately. Process controls and monitors were calibrated and alarms tested. Difficulties with the refrigeration system and centrifuge required the following significant modifications:

- The centrifuge, which had been fabricated by RTC during the first year, was rebuilt four times during the second project year. The final centrifuge design was operable, but it did not provide an optimum ice crystallization environment.

- The refrigeration unit and controls were modified. The final design of the controls and interlocks on the unit performed without failure. The interlocks adequately protected the equipment from damage due to system perturbation. The original refrigeration evaporative system capacity was adequate, but cooling the fluid sufficiently for rapid crystallization in the centrifuge required a sufficiently low temperature. A liquid-liquid refrigeration evaporator was used to cool the water to $32.5^{\circ} \mathrm{F}$. The low temperature resulted in the formation of ice in the refrigerant evaporators, necessitating the addition of another refrigerant evaporator in the centrifuge housing to reduce the ambient temperature within the centrifuge. An air-liquid refrigeration evaporator was used to provide further cooling for the crystallization environment in the centrifuge. The unit operated at design rates with centrifuge speeds up to $200 \mathrm{rpm}$. 


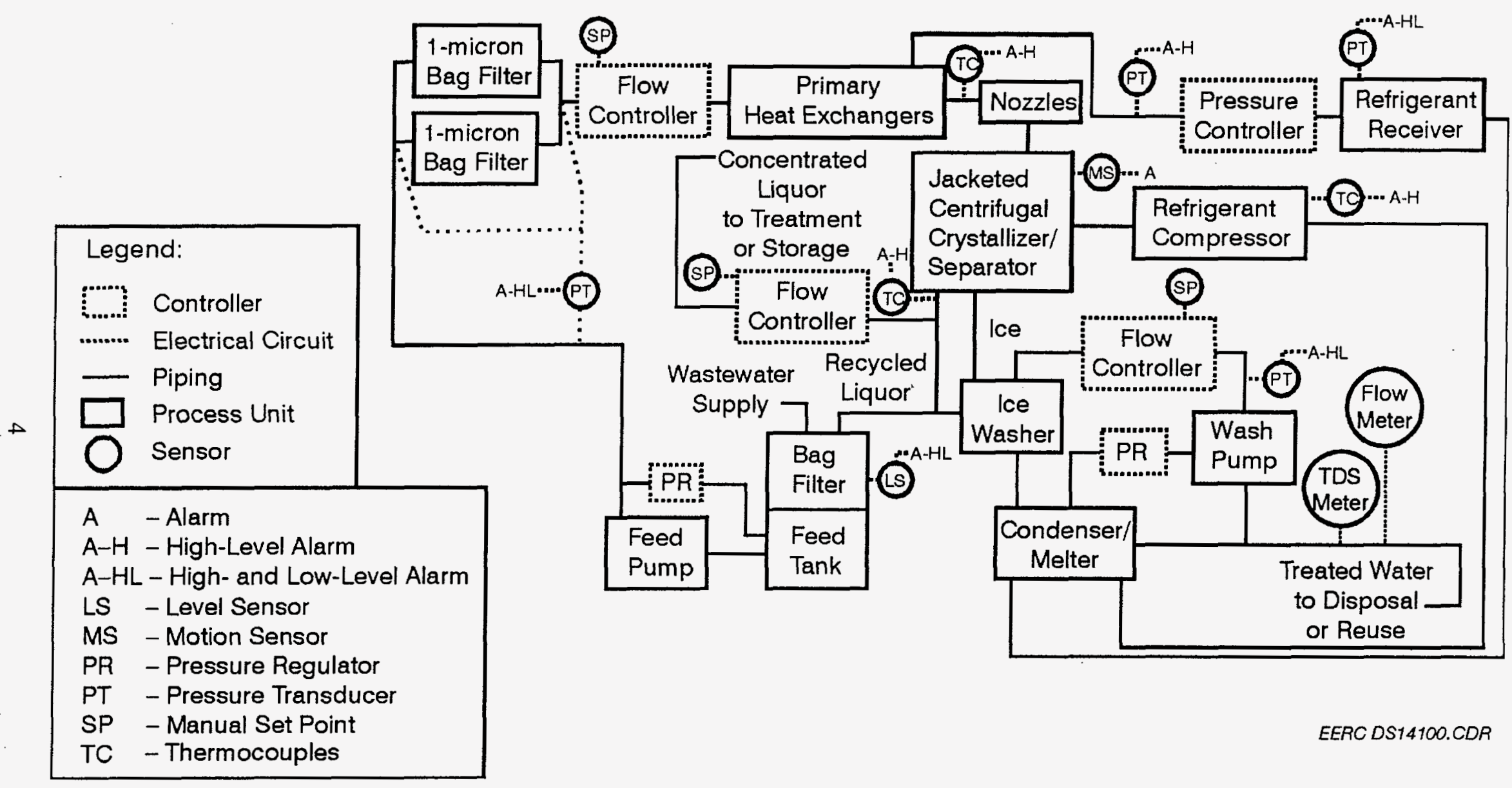

Figure 1. RTC-UNDEERC freeze crystallization water purification process flowchart. 
During the shakedown, the unit was tested with the refrigerant evaporator in both cocurrent and countercurrent configurations. The behavior of the unit with flow rates from 1.5 to 8 gallons per hour (gph) was examined. The prototype flow system was shown to be capable of pumping $12 \mathrm{gph}$, and the unit was capable of making ice at a flow rate of $8 \mathrm{gph}$. The effect of various centrifuge speeds, from 48 to $150 \mathrm{rpm}$, was also examined. The maximum centrifuge speed was found to be $200 \mathrm{rpm}$. Considerable time was spent adjusting the evaporator pressure, which in turn controlled the temperature within the evaporator. The refrigeration system could provide evaporator temperatures as low as $-6^{\circ} \mathrm{F}$.

The ten parametric experiments were performed with varied flow rates of 1.4 to $5.5 \mathrm{gph}$. The centrifuge speed was varied so as to determine the optimum, which was found to be approximately 75 to $100 \mathrm{rpm}$.

\subsection{Prototype Experiments}

Ten prototype experiments were performed for a total duration of 60 hours. During these tests, the EC (electrical conductivity used as an indicator of TDS levels) of the treated water was reduced $30 \%$ to $62 \%$. The ability to concentrate the brine, based on EC, was increased $15 \%$ to $52 \%$ during the prototype tests. Table 1 summarizes the results of the ten prototype experiments.

\section{TABLE 1}

Results of Prototype Experiments

\begin{tabular}{lcccccc}
\hline Test No. & $\begin{array}{c}\text { Feed Flow } \\
\text { Rate, gpm }\end{array}$ & $\begin{array}{c}\text { Test } \\
\text { Duration, } \\
\mathrm{hr}\end{array}$ & $\begin{array}{c}\text { Feed EC, } \\
\mathrm{mS}\end{array}$ & $\begin{array}{c}\text { Brine EC, } \\
\mathrm{mS}\end{array}$ & $\begin{array}{c}\text { Treated } \\
\text { Water EC, } \\
\mathrm{mS}\end{array}$ & $\begin{array}{c}\text { Centrifuge } \\
\text { Speed, rpm }\end{array}$ \\
\hline 16 & 0.092 & 7 & 2.9 & 3.4 & 2.0 & 48 \\
17 & 0.092 & 7.25 & 4.0 & 4.6 & 1.6 & 85 \\
18 & 0.092 & 3.75 & 4.0 & 4.6 & 1.6 & 85 \\
19 & 0.092 & 5.75 & 2.9 & 3.3 & 1.5 & 68 \\
20 & 0.092 & 7.75 & 3.1 & 3.6 & $\mathrm{ND}^{\mathrm{a}}$ & 100 \\
21 & 0.048 & 4.5 & 2.9 & 4.0 & 2.3 & 100 \\
22 & 0.048 & 8 & 3.1 & 3.8 & 1.7 & 80 \\
23 & 0.048 & 8 & 3.0 & 4.2 & 2.0 & 80 \\
24 & 0.00 & 5 & ND & ND & ND & 80 \\
25 & 0.024 & 3 & 2.9 & 4.4 & 1.1 & 80 \\
\hline
\end{tabular}

${ }^{\mathrm{a}}$ No data.

\subsection{NATURAL FREEZE-THAW PROCESS RESEARCH}

The natural freeze-thaw process research was performed to develop and demonstrate a costeffective and viable freeze-thaw process utilizing naturally occurring atmospheric conditions to generate usable water from contaminated groundwater during the winter months at the Strachan Natural Gas Treatment Plant in Alberta, Canada. Specific research objectives included the following:

- Conducting laboratory-scale process simulation for optimizing the design of the freeze-thaw process. 
- Conducting an on-site bench-scale test to demonstrate the technical and economic viability of using the freeze-thaw process to purify contaminated groundwater at the Strachan Plant.

- Developing an economic model to determine the commercial viability, economically significant process parameters, and research issues of the freeze-thaw water treatment process.

\subsection{Natural Freeze-Thaw Process Research Work Plan}

The work plan for the project called for RTC to review the literature and data characterizing the contaminated groundwater produced at the Strachan Plant, survey meteorological data from the region, and identify water quality and atmospheric conditions required for laboratory simulations. The review of the chemical analyses could establish water quality ranges, seasonal variations in water quality and quantity, and expected water production rates at the plant. Meteorological data were also to be surveyed to establish an expected range of atmospheric conditions during the winter months at the plant. The atmospheric conditions surveyed would be used to estimate seasonal, monthly, and daily cycles of wind velocity and temperature. The results of this task were expected to provide an assessment of the concentration ranges of salts, organics, and heavy metal constituents typical in contaminated groundwater. Typical water production rates were also to be determined and atmospheric parameters estimated for the design of freeze-thaw laboratory simulations.

In addition, RTC was to estimate freeze-thaw process discharges and to evaluate regulatory requirements for the bench-scale field demonstration and a large-scale freeze-thaw water purification plant. An estimate of regulated process environmental discharges and subsequent process water treatment, permitting, and disposal costs were required to determine the environmental and economic feasibility of large-scale freeze-thaw water treatment processes.

\subsection{Review of Strachan Plant Contaminated Groundwater Characterization Data}

A review of chemical analyses of $P \& T$ produced water data was conducted to establish water quality ranges, seasonal variations in water quality and quantity, and expected water production rates at the plant.

\subsection{Evaluation of Process and Environmental Constraints}

Preliminary contacts made at the CAPP meeting in April 1993 provided estimates of regulated process environmental discharges and subsequent process water treatment, permitting, and disposal costs. This information is required to determine the environmental and economic feasibility of large-scale freeze-thaw water treatment processes. All contacts provided assurances that freeze-thaw discharges would not be regulated, provided the treated water was of suitable quality for reinjection into the now-contaminated aquifer.

\subsection{Laboratory-Scale Natural Freeze Crystallization Simulation}

Useful data were obtained by conducting a laboratory-scale simulation of a natural freeze-thaw unit. A bench-scale natural freeze crystallization simulation was performed by B.C. Technologies, Ltd. (BCT), to obtain data on process performance. Daily temperatures averaged to 
represent temperatures typical of months with subfreezing temperatures in the area of Rocky Mountain House (located in northern Alberta, Canada) were simulated. Atmospheric conditions for each month with subfreezing temperatures were simulated over a 72-hour period, resulting in a total simulation duration of 21 days. A plot of temperature as a function of time for the duration of the simulation is illustrated in Figure 2. The simulation produced process performance and treatedwater and brine quality data.

At the completion of the simulation, samples from the meit were collected, weighed, combined to form composite samples, and analyzed. The simulation used $47.6 \mathrm{~kg}$ of feed groundwater. A mass balance closure of $97.3 \%$ was attained. Figure 3 plots the EC during the melt. The first $12.0 \%$ of the melted groundwater was collected as brine. It had a composite conductivity of $1890 \mu \mathrm{S} / \mathrm{cm}$. The remaining melt was representative of two fractions of treated water, defined as Treated Water Composite No. 1 (TW-1) and Treated Water Composite No. 2 (TW-2). The next $46 \%$ of the feed that melted was collected and combined as Composite Sample TW-1. The conductivities for the individual samples ranged from 625.0 to $3305.0 \mu \mathrm{S} / \mathrm{cm}$, while the conductivity of Composite Sample TW-1 was equal to $19,254.5 \mu \mathrm{S} / \mathrm{cm}$. Composite Sample TW-2 was made up of the $39.4 \%$ of the feed that melted last. The conductivities of the individual samples ranged from 1974.0 to $3717.0 \mu \mathrm{S} / \mathrm{cm}$, and the conductivity of the composite was equal to $16,512.0 \mu \mathrm{S} / \mathrm{cm}$. Figure 4 illustrates the product water yields.

Samples of the feed and product streams were shipped to the EERC Analytical Research Laboratory for limited chemical analyses. Table 2 shows the results of the chemical analyses conducted on the respective product streams. As can be seen from these results, this freeze-thaw process simulation was effective in remediating contaminated groundwater from the Strachan Plant.

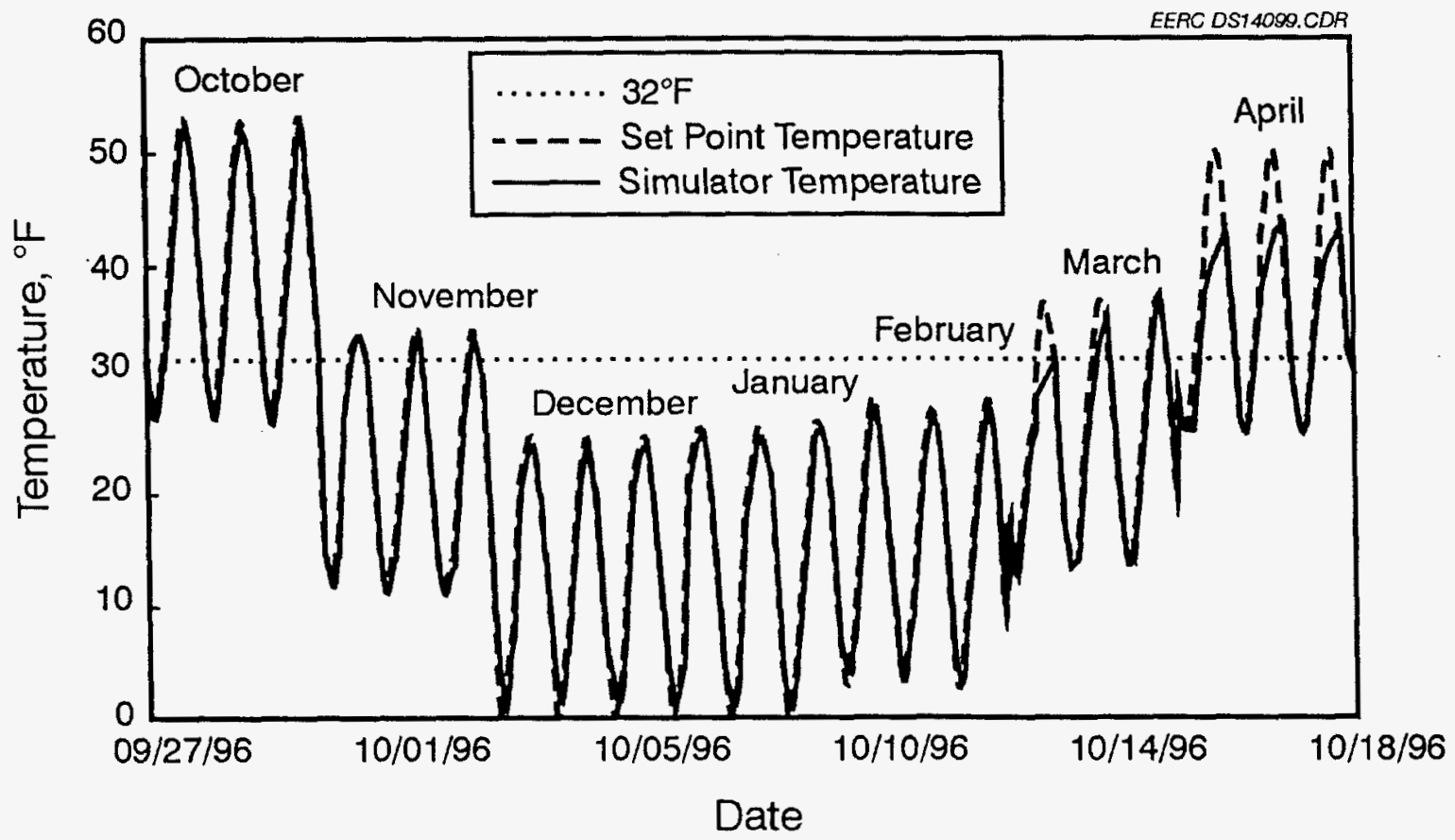

Figure 2. FTE simulator temperature vs. time. 


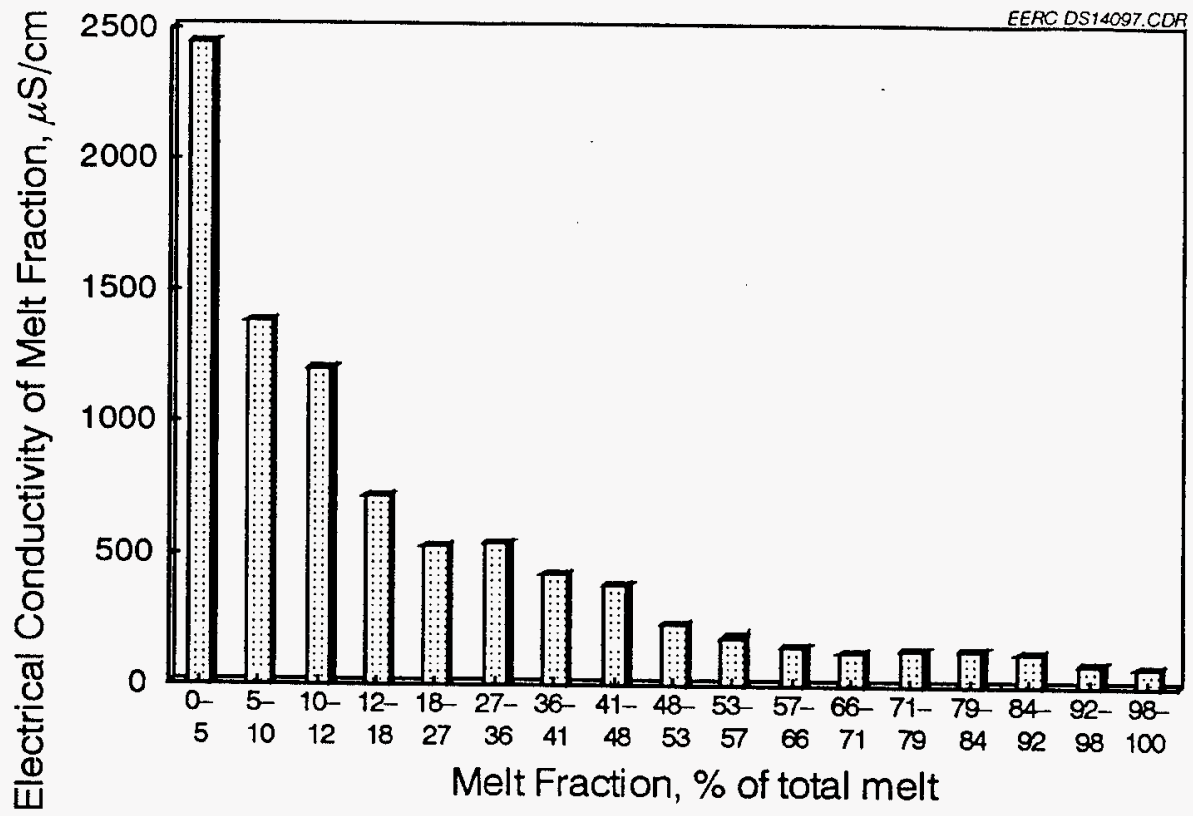

Figure 3. Electrical conductivity of melt fractions freeze-thaw simulation of Strachan Plant P\&T water.

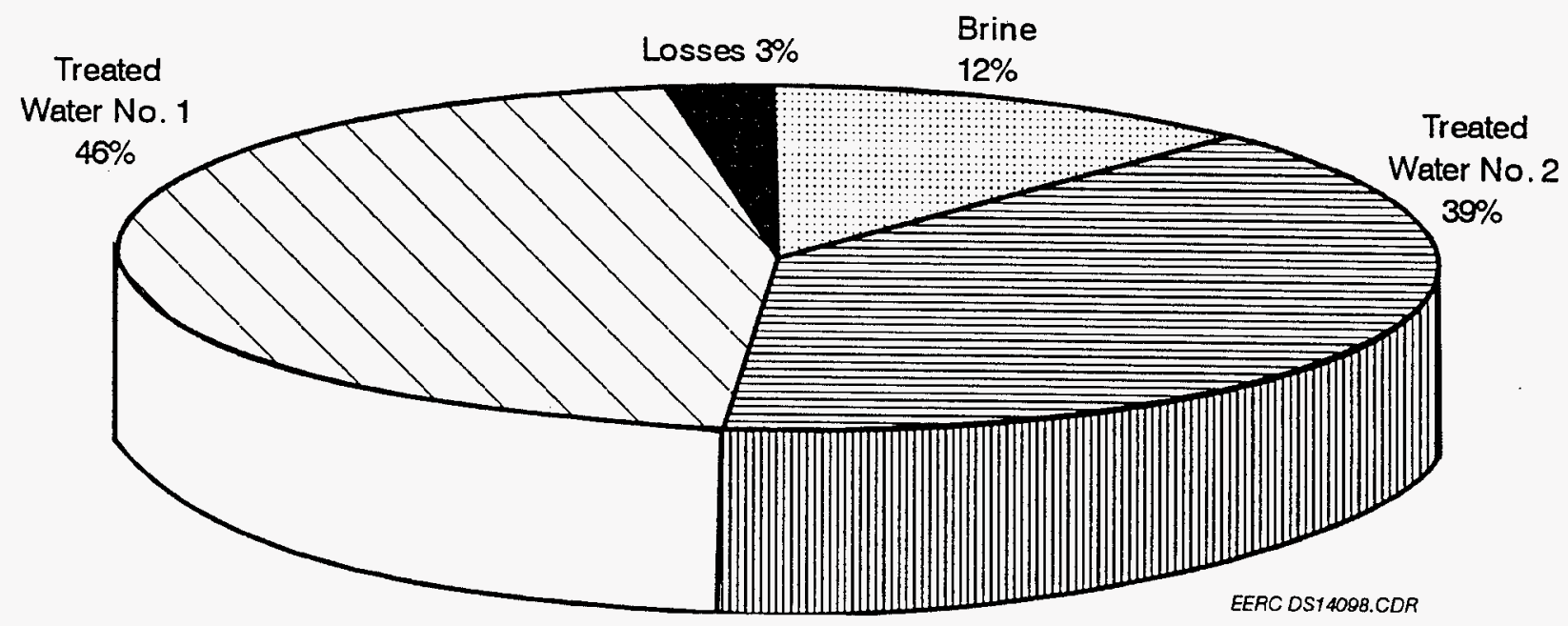

Figure 4. FTE simulation product yield freeze-thaw simulation of Strachan Plant P\&T water. 
TABLE 2

Results of Chemical Analyses of Strachan Plant P\&T

Water Freeze-Thaw Simulation Process Streams ${ }^{\mathrm{a}}$

\begin{tabular}{lcccc}
\hline & Feed & Brine & $\begin{array}{c}\text { Treated Water } \\
\text { Composite No. 2 }\end{array}$ & $\begin{array}{c}\text { Treated Water } \\
\text { Composite No. 1 }\end{array}$ \\
\hline Alkalinity, $\mathrm{HCO}_{3}$ & 648 & 1160 & 291 & 86.2 \\
Alkalinity, $\mathrm{CaCO}_{3}$ & 531 & 998 & 238 & 70.6 \\
Hardness, $\mathrm{CaCO}_{3}$ & 449 & 661 & 178 & 67.2 \\
Ammonia & 0.98 & 4.21 & 0.92 & 0.37 \\
Chloride & 19.9 & 115 & 20.9 & 1.4 \\
Sulfate & 1.5 & 10.4 & 3.5 & 2 \\
Chemical Oxygen Demand & 40 & 170 & 40 & 10 \\
Total Organic Carbon & 100 & 270 & $<100$ & $<100$ \\
Calcium & 119 & 15.7 & 16.8 & 20.2 \\
Iron & $<0.08$ & $<0.08$ & $<0.08$ & $<0.08$ \\
Magnesium & 36.9 & 151 & 33.1 & 4.08 \\
Sodium & 41.7 & 214 & 36.6 & 1.7 \\
Total Dissolved Solids & 576 & 1240 & 317 & 100 \\
Conductivity at $25^{\circ} \mathrm{C}, \mu \mathrm{S} / \mathrm{cm}$ & 994 & 1890 & 481 & 139 \\
\hline
\end{tabular}

${ }^{a}$ All values in $\mathrm{mg} / \mathrm{L}$ except conductivity.

\subsection{SUMMARY AND CONCLUSIONS}

\subsection{Artificial Freeze Crystallization Water Purification Process}

The work effort related to the development of the natural freeze crystallization water purification process can be summarized as follows:

- A prototype of the RTC-EERC artificial freeze crystallization process was constructed.

- The prototype of the RTC-EERC artificial freeze crystallization process was shaken down and modified, resulting in an operational prototype.

- A series of ten experiments were conducted to begin the optimization of the RTC-EERC artificial freeze crystallization process.

The following conclusions were drawn from the results of the artificial freeze crystallization water purification process research:

- A much greater pressure than was expected is required to prevent icing in the water side of the refrigerant evaporator system. 
- The design of the centrifuge and ice scraper system is probably not the optimum required for the artificial freeze crystallization process.

- Although operation of the artificial freeze crystallization process prototype has not been optimized for the treatment of groundwater, the process is capable of removing significant quantities of contaminants from groundwater.

- The operating pressure of the feed water in the refrigerant evaporator heat exchangers, the maximum speed of the centrifuge, and the performance of the ice scraper and ice removal system for the centrifuge must be increased to improve the operability and efficiency of the artificial freeze crystallization process prototype.

- Another air-liquid refrigerant evaporator should be added to the centrifuge housing of the artificial freeze crystallization process prototype to improve the operability and efficiency of the process.

\subsection{Natural Freeze Crystallization Water Purification Process}

The work effort related to the development of the natural freeze crystallization water purification process can be summarized as follows:

- Chemical analyses from the groundwater produced from the Strachan P\&T system were reviewed.

- The regulatory climate in Alberta, Canada, was evaluated with respect to the natural freeze crystallization process.

- Meteorological data were obtained for Rocky Mountain House, Alberta, Canada, and compiled to produce monthly estimates of daily average temperature cycles for use in the laboratory-scale natural freeze crystallization simulator.

- A 21-day simulation of the natural freeze crystallization process was completed using samples of contaminated groundwater from the Strachan Plant.

- The sample tested in the laboratory-scale simulation process did not contain iron, previously a problem in the treatment of this groundwater.

The primary conclusion drawn from the results of the natural freeze crystallization water purification process research is that the natural freeze crystallization process appears to be suitable for use in treating the Strachan Plant contaminated groundwater, but additional laboratory-scale simulations should be conducted to provide additional information regarding the behavior of organic compounds. 


\subsection{RECOMMENDATIONS}

\subsection{Artificial Freeze Crystallization Water Purification Process}

Major strides were made in developing the RTC-EERC artificial freeze crystallization water purification process, and the potential for commercial use of the process is very promising. Additional development is needed to improve the economic viability of the prototype, including further modification of the refrigeration unit and purchase of a new centrifuge. If the feed pump were replaced with a unit capable of operating at $300 \mathrm{psi}$, then the prototype could be operated at significantly lower evaporator temperatures without freezing the feed stream.

The fact that the prototype is operational, potential markets for this water treatment process exist, and promising research results have been obtained indicate that it would be prudent to continue to invest in the development of the artificial freeze crystallization process.

\subsection{Natural Freeze Crystallization Water Purification Process}

The natural freeze-thaw process has been shown to be capable of adequately treating significant quantities of contaminated groundwater from the Strachan Plant. Based on the encouraging total organic carbon (TOC) removal attained during the laboratory-scale simulation, it is recommended that more tests be performed to study the removal of compounds such as total petroleum hydrocarbons (TPH), volatile organic compounds (VOC), and semivolatile organic compounds (SVOC).

The natural freeze-thaw process has already been demonstrated on a commercial scale in New Mexico for another project. Based on the size of the Alberta, Canada, gas industry and the favorable climate for freezing, it could be beneficial to apply the technology to the treatment of the natural gas industry's groundwater. Because the natural process has proven to be feasible it is recommended that CAPP consider field-testing a natural unit. 


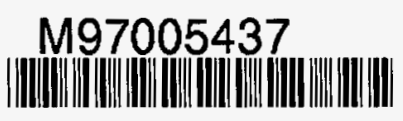

Report Number (14)DOE/MC/30098-- 5722

subl. Date (11) 19970.3

sponsor Code (18) DOE/EE, XF

JC Category (19) Ue-101, DOE/ER 